\title{
The Materiality of Public Participation: the case of community consultation on spatial planning for North Northamptonshire, England
}

Yvonne Rydin and Lucy Natarajan

\section{Introduction}

Within the social sciences, there has been a notable 'material turn', particularly within geography, anthropology and sociology, exploring the implications of the materiality of the world for how we live (Miller, 1998) and know (Latour, 1999, 2007). Anderson and Wylie $(2009$, p. 318) identify three particular clusters of 'materialising' activity: the work on material cultures looking at "meaningful practices of use and encounters with objects and environments"; interest in the "varied intertwined" materialities of nature, science and technology; and the materiality associated with "the spatialities of the lived body, practice, touch, emotion, and affect". Yet the discussion of public participation one of the most significant issues in urban and planning studies - remains largely divorced from these concerns with the materiality of the world. The work of Nortje Marres (Marres 2011, Marres \& Lezaun 2011) is an interesting exception although she focuses on how participation may be understood through technological engagements. Our interest is in considering how the community consultation and engagement activities that take place within current planning processes can be more fully understood through a focus on their materiality. The following analysis, therefore, argues that public participation exercises involve more than just the communicative engagement of social actors with each other. Institutional means of shaping that communication and redressing power inequalities within participatory efforts are important but attention also needs to be paid to how the material is treated, recognised and incorporated as an active agent. Three dimensions of the materiality of such participatory efforts can be identified: the material as being mediated through communities' experience of their environment (Ingold, 2011); materiality as shaping the nature of 
participatory efforts through the physical location, the physical setting and the internal layout (Wates, 2000); and the role played by material artefacts (Bowker and Star, 1999).

\section{The Case Study: spatial planning in North Northamptionshire, England}

The case study concerns the review of the spatial plan for North Northamptonshire in England in the period 2008-12. The area involved comprises just under a thousand hectares to the north of the county of Northamptonshire with a total population of just under 295,000 in 2005 . There are three main towns - Corby, Kettering and Wellingborough - together with over a hundred smaller settlements.

The spatial plan, the North Northamptonshire Core Spatial Strategy was prepared by an ad hoc planning unit the North Northamptonshire Joint Planning Unit (JPU) established by the Borough Councils of Corby, East Northamptonshire, Kettering and Wellingborough. Central government legislation (Planning Acts of 2004 \& 2008, and Localism Act 2011) required a spatial plan setting out the desired future pattern of development to be drawn. Community consultation was a statutory requirement, but the JPU had an avowed desire to make the new core strategy "a 'bottom up' assertion of how local communities want to see their places shaped over the next 20 years" (NNJPU, 2009, p. 2). The main substantive period of community engagement was undertaken in 2011.

The case study was originally researched during 2009-12 through interviews, document analysis and participant and non-participant observation as well as a validation workshop, all centring on the community engagement processes involved in developing the spatial plan review. All material was recorded and systematically coded and stored for later retrieval.

\section{Communities' engagement with their environment}

One of the key reasons for engaging with local publics during consultation exercises - from the viewpoint of both planners and local communities - is to access and express their experiences and knowledge of the local area. The starting point for the communities in the case study was a 'lived' account of the issues that local people were experiencing based on everyday encounters with the 
materiality of their environment, understood through their own bodily materiality (Urry and Macnaghten, 1998). This had a number of implications.

One important feature is that the community does not experience or present itself as an aggregate with one common experience of local environmental materiality. Rather the nature of individual people's engagement with their environment and how they construct this for the plan-making process can be very specific and personal. Examples of such lived experience included: costs of transport; policing; parking difficulties; sites with poor pedestrian safety records; cycling routes; places with litter problems; and ease of recycling (or not). Therefore different people offered apparently contradictory messages for the planners. For example, some people felt their bus services were "good quality" and others that they were "overfull" and "unreliable"; again, some considered that there were "enough shops here to bring people from out of town" and others said that they "need a broader range of shops". The knowledge of local experiences from the community, therefore, had to be generalised into a collective form of knowledge about the balance of experiences in the area, which could be used in the planning process.

Furthermore these relationships are value-laden. The way that community experience of the environment is conveyed explicitly combines values with knowledge. 'Place' was the key trope within community consultation signalling recognition that the local environment carries meanings for people. Such encounters are not just experiential and value-laden but also affective (Healey, 1987; Sandercock, 1998). When people discussed 'their' place they had strong views on the assessment of the character of the area, itself an interesting anthropomorphisation. Using different language, people felt they had 'invested' in the existing environmental assets, both financially but also emotionally. Such attachments lay behind the identification of local heritage and natural assets for protection, but these attachments to local material assets had to be linguistically translated to become relevant to the plan-making process. The emotional attachments to particular buildings and places had to be reframed in terms consistent with heritage and nature conservation policy. 
An interesting feature of community representations on their lived experience within a particular material environment was that they were intrinsically holistic. Community actors tended to situate problems within daily life and, by doing so, they brought out how impacts of one policy area crossed over into another. An example of this concerned the multiple links between developing an evening economy, the quality of the public transport service, safety and policing concerns; the experience of socio-material practices ran across the divides between 'economy', 'transport' and 'crime' in the planning discourse. Similarly affordable housing was linked to the movement of higher educated households out of the area, school bus routes were connected to traffic and parking difficulties, and bus routes were discussed in relation to the location of affordable housing.

There is often an assumption that community-based knowledge of the material environment, precisely because it is based in personal experience, must be purely local in nature in the sense of being limited to the immediate locality of that experience. However, the North Northamptonshire case shows clearly - and to the contrary - that such mediation of the local environmental materiality through a community's experience can include an appreciation of multi-scalar dimensions. The local that was experienced by community members was not conceived of in insular terms. Rather the spatial configuration of personal relationships (i.e. who lived where and how they could connect with each other, travel to each other and act together) formed a large part of the thinking around most topics discussed. Thus the way that publics presented their relevant experience, perhaps surprisingly, had much in common with the conceptualisation of flat space in Deleuzian relational geography (Hillier, 2011).

Discussion between community representatives and planners saw local people widening the area that they were discussing from their home town or village to encompass more distant locations as part of the 'place' that they lived in. For example, some Wellingborough residents expressed their need to access Northamptonshire more generally and saw their specific towns as integral to the subregion. Accessing services on a wider scale was a key element of this broader notion of place, e.g. 
schools in Barton Seagrave for Burton Latimer children. In addition, community representatives readily recognised and articulated the needs of diverse communities (in the plural) across space, usually sorting them into groups such as young people or low income households.

Thus the material environment was mediated by community representatives in ways that both emphasised the fine grain of their personal experiences and connected these across space, with an appreciation that different pictures of their experience emerge at different scales. There was a latent agency of the local materiality which surfaced during the discussions with planners at participatory events and perspective on the environment conveyed in consultations was both strategic and localised, as well as personal and generalised. The reliance on personal experience to ground community representatives' accounts of their environment was extended by empathetic understanding of other people's experience. People were speaking beyond their immediate experience and for a range of other people.

\section{The materiality of the participatory encounter}

The JPU's Participatory Action Plan proposed using a variety of media for engaging with the local communities: public events, press releases, statutory notices in local newspapers, website publication of outputs, post and electronic communications. This section examines those in the participatory encounters at a roadshow, and a 'youth conference' workshop for 10-17 years olds.

The aim of the youth conference was to bring together young people from across the sub-region. It was held one Wednesday evening in October 2011 in a youth centre in Corby, about 10 minutes from the railway station and just off a main road. This was a large assembly hall with a cafe at the back and a games room to one side. The room was set out with a number of tables for groups of about 6-10 people with pens, maps, paper and post-it notes available. Each table seated people who were from the same town or village and the hall was fairly full. Pizza was served on the stage for the young people to help themselves. After an initial talk, given by the younger planners in the professional team, the participants were asked to discuss a series of questions. Facilitators from 
Groundwork (an NGO) sat with the groups, circulated the room, and helped with the final Q\&A session.

Initially there were some inhibitions among participants. However, the atmosphere soon changed to one of excitement and the entire event ended up having the atmosphere of a 'special' or 'different' evening out. The provision of pizza helped here as did the general sense of 'hanging out' with other young people. Photographs were taken at the end of the event to 'commemorate' the activity. It was also helpful that this was a mid-week evening, not an evening when something 'cooler' would be happening. The venue was contributory to successful engagement, as it was decorated by young people for their use and it was home territory for those from Corby. This brought home the message that they were being involved in something that affected their own lives. It also helped them not to feel shy. Indeed the group work involved even led to some exhibitionism.

The material elements of the maps and the pens were central-some vied to get control of the pens and thereby dominate the group. The physical organisation around tables was important in generating enjoyable discussion and helped them feel comfortable in being the focus of attention when speaking. Sitting around the table, they focussed inwards on items and activities on the tabletop. The colourful post-it notes and pens (big fat ones, scattered on the table top for use) were contributory because they could be used to label and write on the map, to 'desecrate' it and forcefully indicate what was important.

\section{[INSERT FIG 1 ABOUT HERE]}

This contrasted with the workshops for $16-18$ year olds held at the end of the afternoon, usually in a school hall or classroom and facilitated by planners. The events also had a rather different feel because they were held in school with teachers present and sometimes with the participants still in uniform. The space was a better quality space than the youth centre but it was not 'owned' by the participants in the same way. The result was a less exciting event. 
Turning to the road show, the planners visited busy public spaces in the 12 largest settlements in the area between during February and March 2011. From 9am to 5pm at busy points within covered shopping malls, sports facilities, churches, hotels and libraries, they set out a table and display boards with maps, the 'Issues Report' and other documentation. The planners, and sometimes also local councillors and other collaborators, stood in front of the table and engaged passers-by in faceto-face discussions. A few chairs were provided but generally people did not sit down; in one venue there were some sofas available with the result that sometimes community participants stayed a bit longer.

\section{[INSERT FIG 2 ABOUT HERE]}

Given the time of year venues were cold, despite this people stopped and were engaged in conversation throughout the period. The materials on display and particularly the prominent JPU logo initiated discussions, with queries as to their purpose. They also acted as props provoking people to voice opinion, for example on their meaning. The materiality of the road show set-up and these material props were clearly central in forming the conversations as well as the participatory encounter. Materials were also involved in recording these discussions. People either wrote down their own opinions, views and conclusions from the discussions, or planners acted as scribes. A record of key points was made on two large flip charts, becoming part of the material that prompted passers-by to stop, engage and comment further. The flip chart symbolised the public importance of discussion in a material way.

\section{[INSERT FIG 3 ABOUT HERE]}

Thus the materiality of the participatory encounter - the sites, their layout, the use of tables and chairs, the means of recording and physically signalling public debate - were all central to creating relationships within that encounter and to shaping their nature. 


\section{The role of material artefacts}

A wide variety of documents and other paper artefacts were used within the engagement process. Among these, the role of maps, scenarios and ideas diagrams were particularly significant. Maps were probably the single most significant type of artefact and used continuously throughout the public engagement process.

Large maps (typically A2 size) were pinned up, read, referenced, pointed at and written on. This eased interactions, especially by helping to avoid jargon in discussions. The maps usually had an Ordinance Survey base, but always had the outline of the local authority boundaries and frequently many more mark ups for instance indicating rivers, green space or new developments. These required some explanation by planners and thus created a starting point for discussion. People could use them (literally) to point to aspects of their lived experience but maps also remained a core tool of professional culture.

\section{[INSERT FIG 4 ABOUT HERE]}

Ideas maps were also used extensively. These had a map base with little detail; the emphasis was on the various symbols, colours and lines indicating different possibilities for the future of the subregion. They were designed to enable discussion spatial patterning of development with stakeholders and would underpin the key diagram required for the final plan. For communities the abstraction of these diagrams required more interpretation by the planners as they were 'visual jargon' with little immediate meaning and varied readings. They held meaning for policy stakeholders and were effective in other elements of planning process, but much less so for public engagement. People found 'real' maps easier to link to their lived experience, but planners then had to translate those views, insights and knowledge into more stylised artefacts for the final planning documentation.

A breadth of other artefacts was used in public engagement and drawings were particularly powerful. Innovative new sketches conveyed some of the deliberative work the planners had been 
doing prior to the community engagement stage. A freelance illustrator had produced a series of images to capture their discussions in hand drawn colour cartoon style. Planners found this output engaging, and created $\mathrm{A} 2$ size posters of them for the roadshow. This also helped signal that the 'stand' was live and interactive.

Back in the planning office the anchor document was the Core Strategy. All the fruits of the consultation had to be mapped onto the topics and issues to revise this Strategy. Thus a key artefact that sat between the public consultation and the next stages of producing the revised plan was the Issue Report. At the road show over 1500 copies of the Issues Report were distributed. It identified five major issues: Growth; Coalescence; Distribution depots; Green network; and Self-sufficiency. Consultation with the communities was more open-ended and tended to be topic based - housing, services, employment, transport, etc. - so a key task during and after the consultation exercises was the linguistic reframing of topics and experience-based views from the public into points of relevance to the five issues set out in the Issue Report. Given the scale and geographically disparate nature of the consultation, this remained a back-office activity rather than part of the public participation itself.

\section{Conclusions}

The case study of plan-making in North Northamptonshire has shown the value of focussing on the materiality of public participation to understanding how community engagement actually operates and intersects with policy development. It has identified the importance of sites and artefacts in the consultation activity and how these contributed in mediating the communities' experiences of their local environment. The grounded, finely-grained, value-laden, affective and sometimes contradictory nature of the knowledge that emerges has been emphasised. However, it has also been shown that community-based knowledge can be multi-scalar and represent multiple sectors in society rather than being narrowly-NIMBY in its framing. The materiality of the participatory encounter was significant; the rooms, the tables, the chairs, the pens all exercised agency. The importance of maps 
in particular as mediating artefacts was demonstrated with the potential to annotate and 'desecrate' giving voice to community perspectives. In particular 'real', OS-based maps were most effective in bringing the public into planning discussions. Not all graphical material was able to play this role as some took the form of 'visual jargon' and was more exclusionary. Repeated transfers of community views from and to post-it notes, postcards, flipcharts, etc. was part of the repeated rounds of material practice that constitute public participation. Clearly, playful materials and physically interactive artefacts were critical to stimulating participation and particular maps helped engage the lived experience in the discussions. However, there remained a critical stage of linking participatory encounters and materiality to the culture of planners' practice, 'back in the planning office', with key rewordings and redrawings. Here the outputs of community participation would be brought together with the prior framings of the plan and key issues to be transformed into a record of influence on the wording and content of the plan.

This suggests that, as a participatory strategy, attention should be paid by planners to the materiality of encounters, how these shape consultation processes and relate to their own planning practices. Public participation is a set of associations collectively created by local people, planners and the material elements of the participation sites, aides and artefacts. If these sets of associations differ, then so will the dynamics and outcomes of participation exercises. What if local people had been taken on field trips or planners on trips to learn about community experiences? What if the young people were given videos and cameras to record their views on their locality and how it should change? What if maps were not used and artists recordedthe sessions? What if community events were held in planning offices or on the site of a development scheme? What if artefacts of participation were recognised forms of planning evidence? Practical considerations and familiar engagement modes can dominate in selecting participatory techniques and tools, but it needs to be acknowledged that the materiality of public participation makes a difference in terms of who is involved, how they are involved, what kinds of views, opinions and values are expressed and how knowledge of the local environment is created and framed for planning discussions. Future research 
on public participation would do well not to continue the silence on its materiality but rather to actively engage with it and embrace the insights that it offers.

Yvonne Rydin, Professor of Planning, Environment and Public Policy, Bartlett School of Planning, University College London

Lucy Natarajan, Research Associate, Bartlett School of Planning, University College London 


\section{References}

Anderson, B. \& Wylie, J. (2009) On geography and materiality. Environment and Planning A. 41.2, 318-335.

Bowker, G.C. \& Star, S.L. (1999) Sorting things out: Classification and its consequences. Cambridge, MA, MIT press.

Healey, P. (1987) Collaborative Planning: Shaping Places in Fragmented Societies. Palgrave: London.

Hillier, J. (2011) Strategic navigation across multiple planes: towards a Deleuzian-inspired methodology for strategic spatial planning. Town Planning Review. 82(5), 503-527.

Ingold, T. (2011) Being alive: Essays on movement, knowledge and description. London, Routledge.

Latour, B. (1999) Pandora's hope: essays on the reality of science studies. Cambridge, MA, Harvard University Press.

Latour, B. (2007) Reassembling the social-an introduction to actor-network-theory. Oxford, Oxford University Press.

Localism Act (2011). London: The Stationery Office.

Marres, N. (2011) The costs of public involvement: everyday devices of carbon accounting and the materialization of participation. Economy and Society. 40.4, 510-533.

Marres, N. \& Lezaun, J. (2011) Materials and devices of the public: an introduction. Economy and Society. 40.4, 489-509.

Miller, D. (1998) Material cultures: Why some things matter. Chicago, II, University of Chicago Press.

NNJPU (2009) A Place Shaping Approach to Joint Core Strategy Review in North Northamptonshire: Summary Proposal for discussion.

Planning and Compulsory Purchase Act (2004). London: The Stationery Office.

Planning Act (2008). London: The Stationery Office.

Sandercock, L. (1998) Towards cosmopolis: planning for multicultural cities. John Wiley: Chichester, Hants.

Urry, J. \& Macnaghten, P. (1998) Contested natures. London, Sage.

Wates, N. (2000) The community planning handbook: how people can shape their cities, towns and villages in any part of the world. London, Earthscan. 